\title{
The WTO: A Spectre, But at Which Feast?
}

\section{Christopher Stevens*}

\section{Introduction}

The World Trade Organization (WTO) stands accused of tying the hands of those governments in sub-Saharan Africa (SSA) that wish to protect their domestic producers from subsidised agricultural imports. The dubbing of the current negotiations as the Doha Development Round is viewed with scorn and its anticipated results with apprehension.

How well placed are such concerns? The answer suggested in this article is that the negotiations under Doha are of considerable importance but the current discourse risks undermining Africa's effective participation. In brief, the critics are tilting at shadows; they are facing away from the real problems that are creeping up behind. The key concern is to begin the process of creating differentiated rules for international trade that reflect concrete differences of circumstance for countries and socio-economic groups.

\section{WTO rules and African food security}

\subsection{How the rules are created}

Unless and until the Doha Round is completed there will be no major new multilateral rules affecting multilateral trade unless these are "created" through dispute settlement. The last major set of rule-making negotiations, the Uruguay Round, was completed in 1994. Countries were given a period of time to implement the agreed changes but, in most areas, these implementation periods have already expired or are close to expiring.

This does not mean that all countries in the world now rigorously adhere to the set of rules that emerge from the Uruguay Round; far from it. There are at least three reasons:

1. Many WTO texts are vague (because the negotiators could not agree on a precise formulation) and different countries are interpreting their requirements in different ways; they cannot all be right.

2. Some countries are behind schedule in implementing the commitments they acknowledge exist.

3. Others are simply ignoring the rules.

There exist a host of examples of patchy implementation which can continue indefinitely unless and until a WTO member decides to take a trading partner "to court" by referring the matter to the WTO dispute settlement regime. Only when this happens is a quasi-judicial verdict given on whether or not the defendant is, indeed, complying with the rules. If it is not, pressure can be exerted on them to do so.

Because of this, it is almost always wrong to state that government X cannot do Y because it is disallowed by the WTO. Only in cases where a dispute has proceeded to judgement will the statement be literally true. On the other hand, it may be the case that indirect pressure is brought to bear on government X not to do Y, whether through a threat by a powerful trading partner that failure to comply will result in a WTO dispute, or through a donor agency arguing that compliance is "good for you".

New rules are created through lengthy negotiating Rounds. The current one was launched at the WTO's biennial Ministerial Conference in Doha in 2001. It is already well behind schedule.

Doha completed the first of three steps in the Round: agreement on the areas in which there will be negotiations and the timetable. The second step is to agree what is known in the jargon as "the modalities" and set the parameters within which countries have to change policy. How many tariff lines are to be liberalised by how much, which

IDS Bulletin Vol 36 No 2 June 2005 @ Institute of Development Studies 
subsidies are to be reduced, etc. The last stage involves bilateral negotiations between each WTO member to establish exactly how the modalities are to be applied in each specific country.

The most recent step in the negotiations occurred in July-August 2004 when a Ministerial meeting finally agreed not to the modalities but, at least, a stepping stone towards them. This is described in the rest of this article as the 1 August 2004 Decision. The stage is now set for the next biennial Ministerial (Hong Kong at the end of 2005) to agree the modalities after which the last phase of negotiations can commence.

\subsection{Difficulties creating special and differential treatment (SDT)}

As long as the rules are vague, partial and patchily implemented, their failings may not pose problems. But as they become more precise, constraining and encompassing, anything in them that is inappropriate to SSA circumstances becomes more dangerous. Appropriate differentiation and nuancing - such as is the norm in the domestic regulations of every state, especially the richest becomes essential. It is known in the jargon as SDT.

While the WTO negotiations pay lip service to the notion of SDT, there is no clarity on how it can best be operationalised because of misunderstandings and disagreements over the role of international trade policy in fostering food security and a vigorous rural sector.

\subsection{The systemic problems}

There are two systemic problems that bedevil the creation of effective SDT. One is a particular concern for agriculture. It is that the current Agreement on Agriculture aims to solve a problem that most developing countries do not have. It is the problem (prevalent in the Organisation for Economic Cooperation and Development (OECD) states) of heavy direct and indirect distortions to their domestic agriculture that have significant effects on the world market. Consequently the Agreement on Agriculture SDT is couched in terms of moderating the implementation of rules designed to cure this irrelevant problem rather than dealing with the problem that most developing countries do have - which is one of agricultural sectors that are less robust than they can and should be.

The second systemic difficulty concerns the decision-making structure within WTO Rounds and applies to all SDT. The Rounds make slow and erratic progress. There can be no agreement until the major
WTO members have obtained compromises with which they can live, and then there is a strong imperative to finalise the deal as quickly as possible before this consensus is disturbed. It is very difficult to insert precise, relevant binding provisions at a late stage in the negotiations (when there is considerable pressure to bring everything to a conclusion) but it is politically difficult to establish at an early stage broader, enforceable commitments that would deal appropriately with any details that are later negotiated. In other words, by the time there exists sufficient clarity about the precise "standard" rules that are being agreed to allow appropriate SDT modulations to be designed, it is too late to do so.

\subsection{Designing SDT relevant to food security}

If current SDT deals with problems Africa does not have, what are the broad features of the modalities that would deal with the problems that it does have? For food security planners and analysts, the concept of food security has evolved substantially in recent decades. ${ }^{.}$The WTO has been left largely behind by a shift in perspective from "self-sufficiency" to "selfreliance" and needs to catch up.

Since the 1980s, the concept of food security has shifted away from the national to the household level, and from the production of food towards access to food. Sen's (1987) entitlement approach has provided a useful analytical framework, in which production was recognised as one of four possible sources of food, the others being trade, labour and transfers. While many countries retain a degree of scepticism about international commodity markets, it is now widely accepted that the various sources of food and income should be seen as additional and complementary, rather than stark policy choices between one or the other.

The "security" component of food security is reflected in the renewed recognition of the importance of livelihood insecurity or uncertainty as central to the experience of living in poverty. Food security is a dynamic concept that implies stability and reliability of access to food over time. At the level of international trade, one reason why developing country governments might resist deepening their "dependence" on global markets for staple food needs is anxiety about supply or demand volatility in those markets.

It is misleading and unhelpful to conflate the WTO with liberalisation. While a change in a country's tariffs is likely to have food security 
The WTO: A Spectre, But at Which Feast?

implications, this is far from being the only way in which the WTO can impinge. The WTO enters the analysis of domestic livelihoods primarily as a change in the "rules of the game". And there are many such rules that can affect entitlements both directly and indirectly through their impact on the latitude open to governments.

WTO rules may bear on four sets of policies, with different probabilities of effect on livelihood and food security: a country's own domestic trade policy, its international trade policy; and its trade partners' domestic and international trade policies. For many SSA states the order of importance is, first, the country's own domestic policy, then its trade partners' policies and, last, its own international trade policy.

Changes to an SSA country's international trade policy have their impact on food security primarily through the effect on the relative prices of things people buy and sell. Anything that is not 100 per cent domestic in content - that is, anything that incorporates any imported or potentially exported element (which usually means anything involving road transport) - may experience altered costs and supplies. The consequences will be felt as a change in the absolute or relative returns to specific production- or trade-based livelihood activities. This may induce producers to shift away from certain commodities towards others, or perhaps to diversify out of commodity production altogether.

But other factors also affect the prices of things people buy and sell and other WTO rules may affect these directly or indirectly. These may reinforce or offset the changes resulting from international trade policy change. Typical examples are domestically oriented trade-related policies (such as on price controls, parastatal policy, etc.), non-trade international policies (such as on the exchange rate and foreign exchange convertibility), and the creation/destruction of institutional infrastructure. In addition, of course, altered government policies may affect the availability of physical infrastructure and supply of transport.

WTO rules on allowable subsidies could affect the feasibility of input support. New rules on state trading organisations could impact on the use of parastatals for domestic as well as international marketing. An undue focus on tariff reduction is very unwise: it can divert attention towards unimportant changes and away from vital ones. Among the latter are those made by SSA's trading partners that will affect the price of agricultural exports and imports. The recent case brought by Brazil against the $\mathrm{EU}$ on sugar, for example, could have the most profound consequences for Malawi, Mauritius, Mozambique, Zambia, Zimbabwe and Swaziland. Changes to world prices as a result of OECD subsidy cuts under Doha may increase the price of SSA imports - with differential effects on entitlements.

\section{Applying the lessons: the example of special products}

If trade rule changes can have multiple, complex effects on food security, the natural response is to seek SDT in the WTO that is either similarly complex (so as to deal with all reasonable situations) or extremely broad (to cover any of the possible effects). But both are extremely difficult to negotiate.

The "complex list" approach risks overlooking many situations (some of which cannot be anticipated until after the ink is dry on Doha) and seeing desirable pro-poverty actions struck down in dispute settlement. The "broad exception" approach is hard to accept for some WTO members (not necessarily only industrialised countries). There can be legitimate food security and livelihood concerns in middle-income, net agricultural exporters as well as in poor, food importers. If the "broad exceptions" apply to the richer net exporters, the industrialised countries will object; if they do not, there could be adverse livelihood impacts.

The task is to identify enforceable SDT provisions that are sufficiently targeted to be negotiable within the WTO but also general enough to encompass situations and problems that have not yet been envisaged. That is a tall order! It is argued by practitioners that it is far easier to develop the usage of an instrument that has already been included in a Decision (in some cases stretching its meaning far beyond what might have been in negotiators' minds) than it is to introduce entirely new principles and concepts into the negotiations.

Because of this, events such as the 1 August 2004 Ministerial Decision are of considerable importance. They provide a set of "pegs" on which SDT principles can be hung. Because the Decision is still couched at a high level of generality (there are, for example, absolutely no indications of by how much either agricultural tariffs or subsidies will have to be reduced) the resulting SDT measures have to be similarly broad. But at least they allow a start to be made on the process. 
With this in mind, what use can be made of one of the two pegs of Special Safeguard Measures (SSMs) and Special Products (SPs) that have been introduced in the Decision? The concept of SPs is the joker in the 1 August pack: it emerged suddenly with no clear guidance of any consensus of their scope and uses. This means that they could be used in some creative thinking. The bulk of this sub-section provides an example, both because it is relevant to SSA and to stimulate further lateral thinking.

Para. 41 of Annex A to the 1 August Decision states that developing countries (and only them) can designate 'an appropriate number' of Special Products which 'will be eligible for more flexible treatment'. All the details of how many products and what sort of flexibility are left to further negotiation.

Among the most obvious food security uses for SPs are:

- to avoid any increase in import competition for products that are particularly important for the rural economy

- to protect government revenue for use on food security expenditure by maintaining tariffs on items that yield significant revenue.

In addition, the very absence of any detail may be used to support more creative usages. The 1 August Decision restricts the selection of SPs to developing countries but it is silent on how the "more flexible treatment" is to be accorded. It does not state, for example, that the flexibility is only to be provided in the developing country's own schedule of commitments. A literal reading of the text, therefore, opens up the possibility that among the "flexible treatment" to be allowed in relation to Special Products that are SSA exports is flexibility on the part of the importing state to design its schedule of commitments in such a way as to support the livelihood objectives noted by the developing country member when it established its Special Product. In other words, it may be possible to use SP as a link to measures in preference-giving countries that might be useful for preference-receiving states.

\section{Next steps}

There is still a great deal to be done to insert into a Doha Agreement measures that would begin the process of making the rules relevant to the circumstance of African agriculture. It will be a struggle - made more difficult because of the highly human-resource intensive system of negotiation within the WTO and the systemic problems that there is no consensus for broad dispensations to be agreed at this stage, but little possibility of devising precise ones by the time the negotiations have reached a point at which this would be feasible.

This simply reinforces the point made at the start of this article, that if African governments, civil society and researchers are looking in the wrong direction, the chances of success are greatly reduced. SDT that would, for example, give all of SSA a moratorium on implementing any of the changes agreed in the Doha Round would be a better outcome than a requirement that they implement quickly wholly undesirable measures - but it would be very much a second best. It would mean that no attention had been given to the task of creating (at least in embryonic form) rules that are relevant to Africa. It would simply defer the problem until the next round after Doha. And it would make that task more difficult (because Doha would have cemented and reinforced the current "one size fits all") OECDoriented nature of the rules.

Given the systemic difficulties of the WTO, the most feasible route for implementation is to start from the bit that Africa knows best: what sort of international environment of rules does its agriculture need in order to thrive? Answering this question does not require researchers or civil society to wait until the Geneva negotiations have reached the details. It involves a parallel process that converges over time with that operating in Geneva. By the time the details of the modalities are being fleshed out, there needs to be a clear statement of what African agriculture needs from global trade rules. The one can then be used to implement the details of the other. 


\section{Notes}

This article draws on Croome (1995); Diaz-Bonilla et al. (2002); Michalopolous (2003: 24-37, 2001); Stevens (2003).

1. See Stevens et al. (2003) for further elaboration.

\section{References}

Croome, J., 1995, Reshaping the World Trading System: A History of the Uruguay Round, Geneva: World Trade Organization

Diaz-Bonilla, E., Thomas, M., Robinson, S. and Yanoma, Y., 2002, 'WTO, agriculture and developing countries: a survey of issues', Trade and Macroeconomics Division Discussion Paper 81, Washington, D.C.: International Food Policy Research Institute

Michalopolous, C., 2003, 'Special and differential treatment in agriculture: proposals for a development round', IDS Bulletin, Vol 34 No 2: 24-37, Brighton: Institute of Development Studies
Michalopolous, C., 2001, Developing Countries in the WTO, New York and Basingstoke: Palgrave Macmillan

Sen, A., 1987, Poverty and Famines: An Essay on Entitlement and Deprivation, Oxford: Oxford University Press

Stevens, C., 2003, 'Food trade and food policy in sub-Saharan Africa: old myths and new challenges', Development Policy Review, Vol 21 No 5

Stevens, C., Devereux, S. and Kennan, J., 2003, 'International trade, livelihoods and food security in developing countries', Working Paper 215, Brighton: Institute of Development Studies 